\title{
Leukocyte Cell Biology
}

National Cancer Institute

\section{Source}

National Cancer Institute. Leukocyte Cell Biology. NCI Thesaurus. Code C19632.

Cell biology studies concerned with understanding the structure and functioning of leukocytes. 